\title{
IMPLEMENTASI E-COMMERCE PENJUALAN JASA CETAKAN PADA GRAHA PRINTING SOLUTION
}

\author{
Agung Wisnubroto ${ }^{1}$, Bruri Trya Sartana ${ }^{2 *}$, Ririt Roeswidiah ${ }^{3}$ \\ ${ }^{12}$ Fakultas Teknologi Informasi, Program Studi Sistem Informasi, Universitas Budi Luhur, Jakarta, Indonesia \\ ${ }^{3}$ Fakultas Teknologi Informasi, Program Studi Teknik Informatika, Universitas Budi Luhur, Jakarta, Indonesia \\ Email: ${ }^{1} 11712501269 @$ @student.budiluhur.ac.id, ${ }^{2 *}$ brury@budiluhur.ac.id, ${ }^{3}$ ririt@budiluhur.ac.id \\ (* : coressponding author)
}

\begin{abstract}
Abstrak-Graha Printing Solution adalah jasa percetakan yang dapat mencetak barang cetakan. Kesulitan yang dialami perusahaan adalah sulit mendapatkan calon pelanggan baru karena berada dilokasi yang kurang strategis yang menyebabkan sedikitnya penjualan serta banyak calon pelanggan yang belum mengetahui jenis bahan produk apa yang disediakan dan dapat memproduksi produk apa saja. Hal ini disebabkan karena kurangnya informasi kepada pelanggan sehingga menimbulkan kergauan untuk mengunjungi toko dan melakukan transaksi. Pada penelitian ini digunakan Business Model Canvas yang dapat menganalisa model pengembangan bisnis yang ada. Dilakukan implementasi E- Commerce berbasis Content Management System sebagai solusi untuk permasalahan yang ada dan memberi kemudahan kepada pelanggan untuk mendapatkan informasi. Implementasi sistem E-Commerce ini dapat meningkatkan daya jual dan pelayanan kepada pelanggan semakin baik serta menyelesaikan masalah yang ada.
\end{abstract}

Kata Kunci: E-Commerce, CMS, BMC, WordPress, SEO

\begin{abstract}
An Graha Printing Solution is a printing service. The difficulty of the company is that it is difficult to get new prospective customers because the store place its not strategic which causes sales decreasing and many prospective customers do not know what type of product material is provided. This because of lack information to customers, causing confusion to visit the stores and to make transactions. The research uses the business model canvas method to analyze existing business development models and the implementation of content management system-based E-Commerce as a solution to existing problems and makes it easy for customers to get information. With the implementation of this ECommerce system, it increases selling power and better service to customers and solves existing problems.
\end{abstract}

Keywords: E-Commerce, CMS, BMC, WordPress,SEO

\section{PENDAHULUAN}

Seiring dengan berkembangnya teknologi informasi masa kini, segala sesuatu banyak dilakukan menggunakan teknologi terutama untuk kegiatan jual beli, dengan menggunakan teknologi internet kegiatan jual beli pun dapat dilakukan dengan cepat dan efisien tanpa harus mengunjungi toko tersebut secara langsung. Graha Printing Solution adalah UKM yang bergerak dibidang jasa percetakan yang memberikan pelayanan untuk mencetak sticker, nota, brosur, hangtag, kartu nama, dan lain lain. Lokasi toko berada di tempat yang kurang strategis yang mengakibatkan sulitnya mendapatkan pelanggan baru dan rendahnya penjualan.

Pada saat ini banyak calon pelanggan yang belum mengetahui jenis bahan produk apa yang disediakan dan dapat memproduksi produk apa saja karena kurangnya informasi kepada pelanggan sehingga menimbulkan keraguan untuk mengunjungi toko dan melakukan transaksi.

Berdasarkan hasil wawancara dan dilakukan analisis, terdapat masalah umum yang dihadapi yaitu kurangnya pemahaman pemilik bagaimana meningkatkan penjualan dan hanya mengandalkan penjualan langsung di toko. Masalah lain adalah kesulitan mendapatkan pelanggan baru yang berada diluar wilayah sekitar, kurangnya informasi jenis bahan yang digunakan sebagai media cetak dan jenis layanan jasa yang tersedia. Tujuan diimplementasikan e-commerce ini adalah dapat memberikan strategi transaksi jasa percetakan di internet untuk meningkatkan penjualan, membantu proses pendataan produk dan transaksi dengan mudah dan efisien, memudahkan penyajian infromasi produk secara detail dan pelanggan dengan mudah mengakses website darimana dan kapan saja.

Pada penelitian [1] terdapat masalah yaitu menghambat pertumbuhan toko yang kekurangan media untuk mempromosikan dan memasarkan produk mereka ke komunitas yang lebih besar. Penelitian ini dilakukan untuk memberikan solusi permasalahan yang ada pada sistem informasi penjualan berbasis CMS berupa e-commerce dan metode BMC. Hasil dari penelitian ini membuat website penjualan berbasis e-commerce yang dapat digunakan dalam media humas, dan pengolahan data. Penelitian yang dilakukan oleh [2] terdapat permasalahan yaitu hanya berjualan melalui telepon atau WhatsApp dan pelanggan tidak mengetahui barang apa saja yang sering ada diskon dan tidak terdapat modul konfirmasi pembayaran secara online. Tujuan penelitian ini adalah 
available online at http://jom.fti.budiluhur.ac.id/index.php/IDEALIS/index

untuk meningkatkan pemasaran produk dan mengetahui pelanggan mana saja yang sudah melakukan pembayaran online. Hasil penelitian meningkatkan pemasaran produk dan menu checkout, dan membuat sistem penjualan berbasis e-commerce.

\section{METODE PENELITIAN}

\subsection{Tahapan Penelitian}

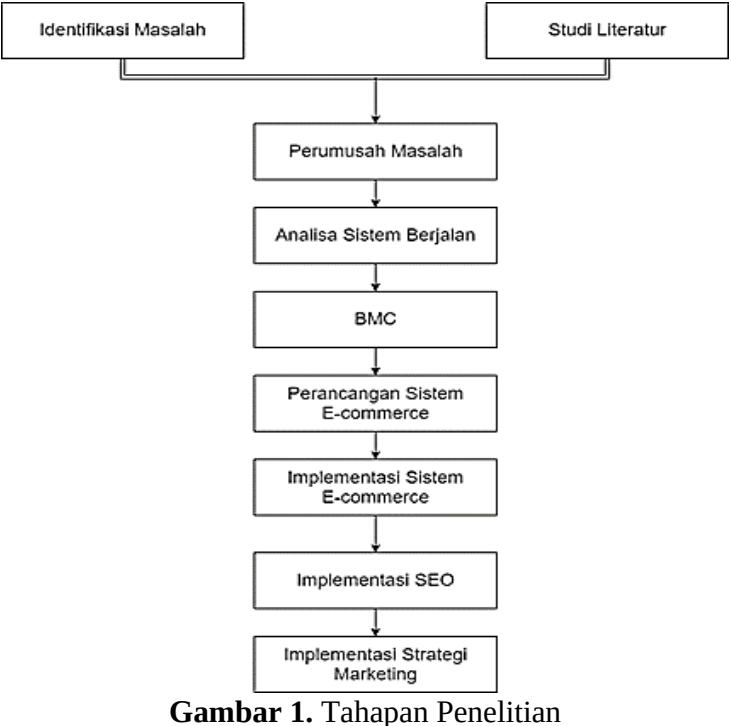

Gambar 1 memperlihatkan tahapan penelitian yang dimulai dengan identifikasi masalah, mengacu pada studi literatur yang sudah ada sebelumnya. Dirumuskan masalah yang terjadi setelah itu dilakukan analisis sistem berjalan. Business Model Canvas (BMC) dibuat untuk mengusulkan model bisnis yang akan diterapkan pada ecommerce. Bila sudah disepakati oleh pemilik, maka dirancang sistem e-commerce, mengimplementasikan SEO serta dimplementasikan strategi pemasarkan(marketing) yang dibutuhkan.

\subsection{Metode Pengumpulan Data}

Agar tercapai tujuan penelitian dilakukan pengumpulan data dengan cara melakukan wawancara pada pihak yang terkait dengan sistem yang akan dirancang, observasi langsung ke toko, melakukan analisis dokumen pada sistem berjalan serta melakukan studi literatur penelitian sebelumnya.

\subsection{Metodologi Analisis dan Penggunaan Tools}

Dengan menggunakan teknik analisis data maka menentukan hasil dari suatu penelitian dengan menyimpulkan hasil dari penelitian, dengan cara mengolah data menjadi informasi sehingga karakteristik dan sifat-sifat data yang dapat dengan mudah dipahami [3]. Tahap awal adalah dengan melakukan analisis masalah, setelah itu dilakukan analisa proses bisnis dengan menggunakan activity diagram. Berikutnya dirancang sistem secara detail berdasarkan analisis terhadap sistem yang berjalan saat ini sehingga dihasilkan model sistem baru. Tools yang digunakan untuk merancang sistem E-Commerce adalah Activity Diagram, Use Case Diagram, Interaction Flow Modeling Langueage, Sequence Diagram, Component Diagram yang digambarkan menggunakan draw.io dan Rancangan Layar yang digambarkan menggunakan Adobe XD

\section{HASIL DAN PEMBAHASAN}

\subsection{Business Model Canvas (BMC)}

BMC adalah model analitis yang menggambarkan ide tentang bagaimana sebuah organisasi atau bisnis menciptakan, memberikan, dan memperoleh nilai bagi organisasi atau bisnis. Gambar 2 menunjukkan 9 bagian Business Model Framework (BMC) [4][5][6].

a. Key Partners/Perusahaan/Partner Kunci 
available online at http://jom.fti.budiluhur.ac.id/index.php/IDEALIS/index

Menjelaskan perusahaan kunci mana saja yang dapat bekerjasama dengan perusahaan untuk membantu aktivitas kunci sehingga tercipta nilai yang diharapkan pelanggan.

b. Key Activities/Aktivitas Kunci

Menjelaskan aktivitas kunci yang dilakukan oleh perusahaan untuk menghasilkan nilai-nilai yang akan ditawarkan oleh perusahaan kepada pelanggan.

c. Key Resource/Sumberdaya Kunci

Menjelaskan sumberdaya kunci di internal yang dimiliki perusahaan. Sumberdaya ini yang akan menghasilkan nilai-nilai dari produk/jasa yang akan diberikan kepada pelanggan.

d. Value Proposition/Nilai yang ditawarkan dari produk

Berisi penjelasan tentang nilai-nilai dari produk/jasa yang ditawarkan kepada pelanggan. Nilai-nilai ini sangat berhubungan konsumen target.

e. Customer Relationship/Hubungan Pelanggan

Menjelaskan strategi perusahaan agar konsumen tidak berpaling kepada produk lain dan lebih mendekatkan konsumen.

f. Channels/Kanal

Menjelaskan media apa yang digunakan untuk menyampaikan nilai-nilai dari produk yang dijual kepada konsumen melalui media

g. Customer Segments/Segmentasi Pelanggan

Menjelaskan segmentasi pelanggan yang akan ditawarkan produk/jasa sesuai dengan nilai-nilai(value)

h. Cost Structure/Struktur Biaya

Menjelaskan struktur biaya untuk menjalankan keseluruhan aktivitas proses bisnis pada produk/jasa..

i. Revenue Stream/Keuntungan Perusahaan

Menjelaskan aliran keuntungan apa saja yang dapat dihasilkan dari bisnis yang ditawarkan.

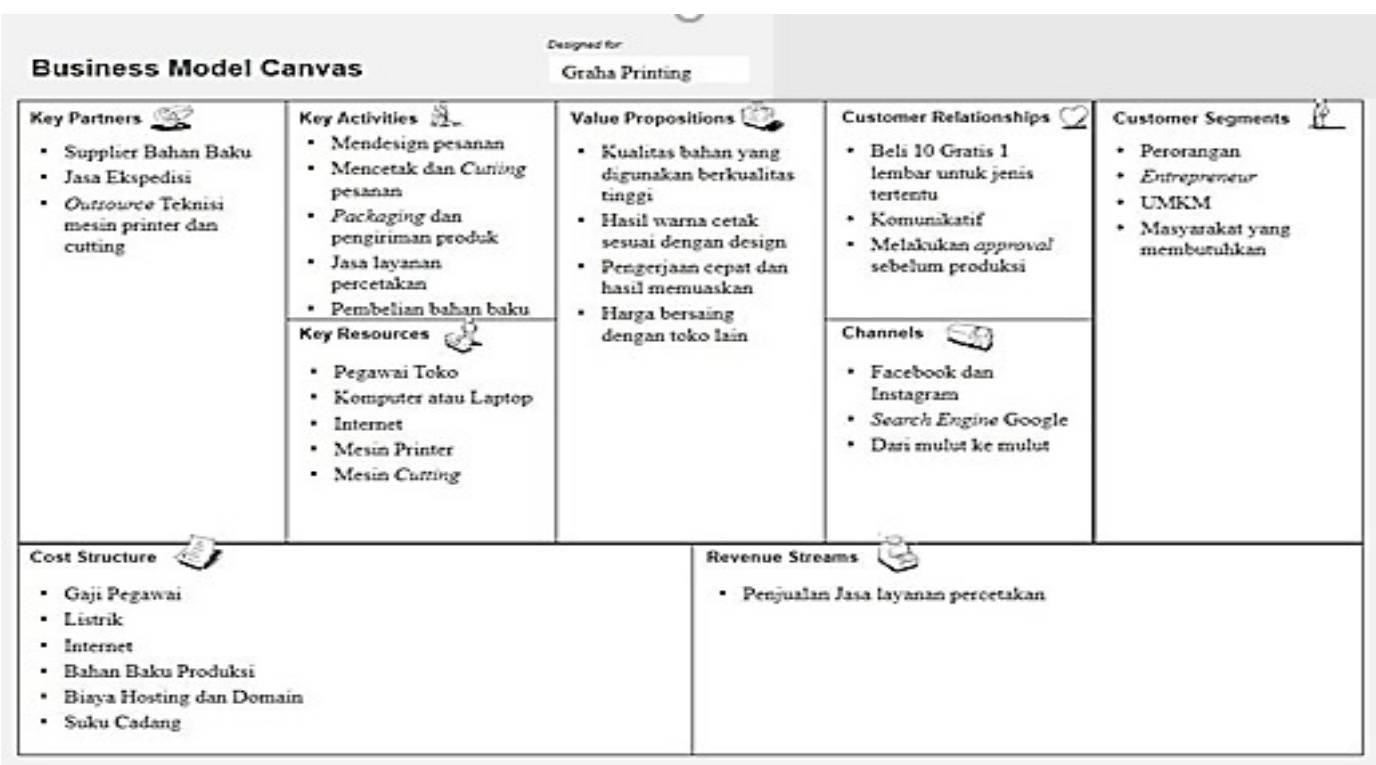

Gambar 2. Model Bisnis yang diusulkan untuk diterapkan dalam bentuk Business Model Canvas

Pada Gambar 2 diusulkan sebuah model bisnis yang dapat menampilkan perbaikan model bisnis yang berjalan agar perusahaan mengetahui nilai apa yang dapat ditawarkan kepada pelanggan serta bagaimana menghasilkan nilai tersebut.

\subsection{Proses Bisnis Usulan}

a. Proses Pemasaran dan Pemesanan Produk

Proses menambahkan produk adalah petugas masuk ke halaman admin website, lalu menambahkan produk, gambar produk, deskripsi produk, harga produk, stok produk, dan kategori produk dengan lengkap. Setelah melengkapi produk pegawai mengklik "Terbitkan" untuk menampilkan produk di halaman websit seperti pada Gambar 3. 


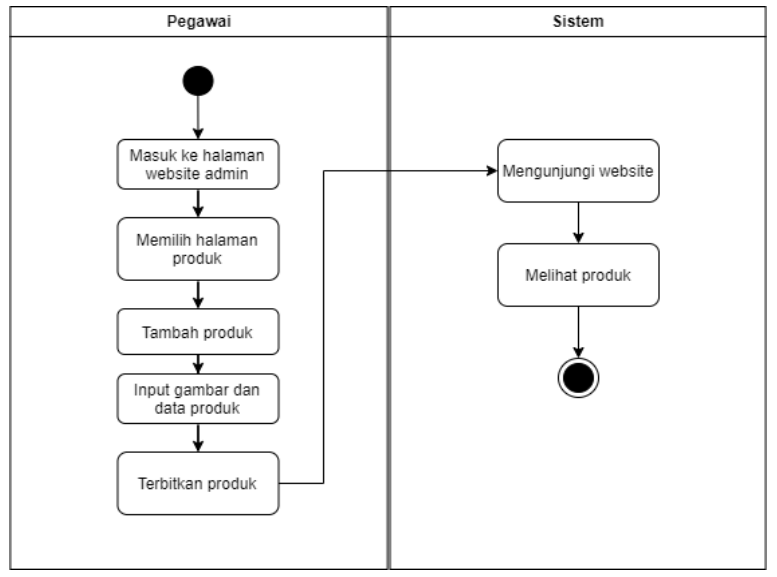

Gambar 3. Proses Pemasaran Produk

b. Proses Pemesanan Produk

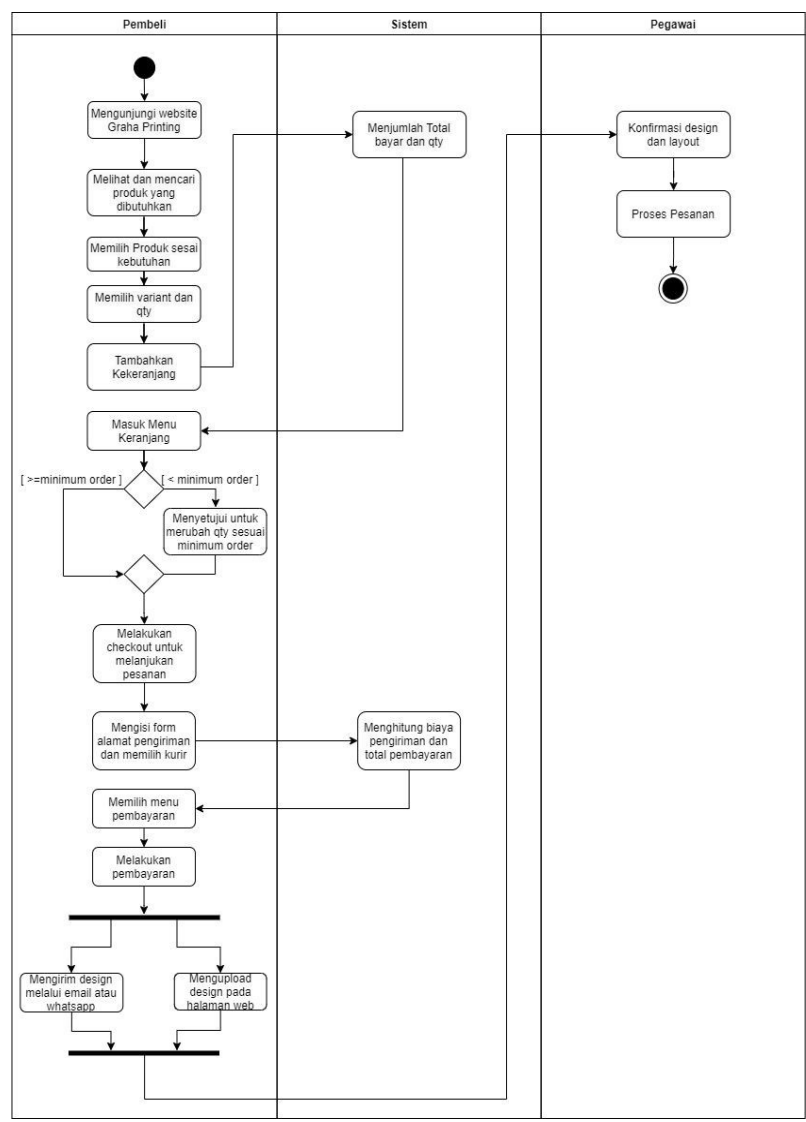

Gambar 4. Proses Pemesanan Produk

Pembeli melihat dan mencari produk sesuai kebutuhan, menginput qty produk yang dibutuhkan kemudian mengklik tombol tambah ke keranjang, setelah itu sistem menjumlah total bayar dari qty yang diinput. Selanjutnya pembeli mengklik menu keranjang yang ada di halaman website, jika qty yang di input kurang dari minimum order pembeli harus merubah qty order sesuai dengan qty minimum order, jika qty order lebih dari sama dengan qty minimum order pembeli melanjutkan transaksi dengan mengklik tombol checkout, kemudian pembeli mengisi form data diri dan alamat pengiriman lalu sistem dapat menghitung biaya ongkos kirim dan total pembayaran, pembeli kemudian dapat memilih menu pembayaran, selanjutnya pembeli melakukan proses pembayaran sesuai dengan detail pemesanan. Setelah melakukan pembayaran pembeli mengirimkan design, melalui upload design pada halaman web 
INDONESIA JOURNAL INFORMATION SYSTEM (IDEALIS)

Volume 4, Nomor 2, Juli 2021

ISSN 2684-7280 (online)

Halaman 197-204

available online at http://jom.fti.budiluhur.ac.id/index.php/IDEALIS/index

atau mengirimkan design email atau whatsapp kepada admin, lalu petugas akan melakukan konfirmasi design dan layout seperti pada Gambar 4.

c. Proses Konfirmasi Pembayaran

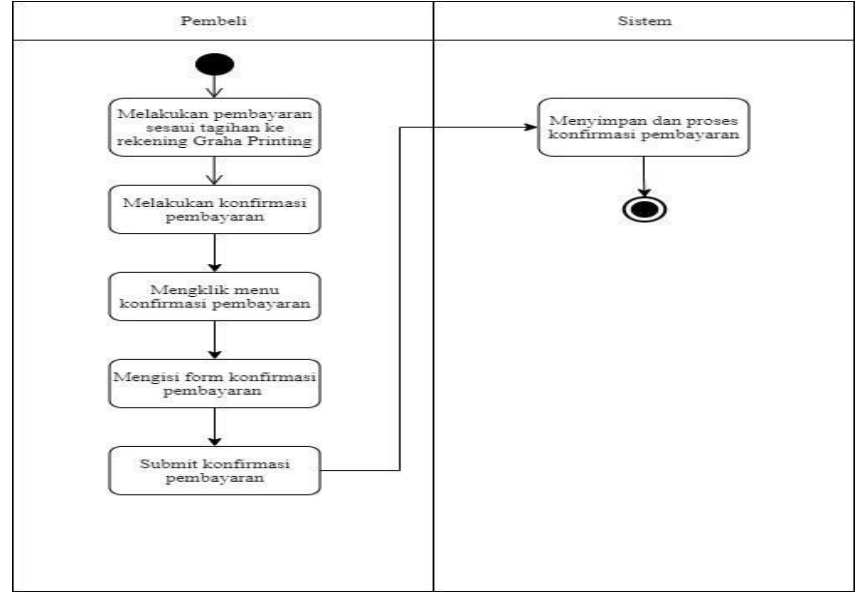

Gambar 5. Konfirmasi Pembayaran dari Pembeli

Kegiatan yang dilakukan pembeli untuk pembayaran dengan cara mentransfer uang ke rekening perusahaan sesuai total pembayaran, setelah itu pembeli melakukan konfirmasi pembayaran dengan mengklik menu konfirmasi pembayaran pada halaman website, kemudian pembeli mengisi form yang terdapat pada menu konfirmasi pembayaran dan klik submit maka sistem akan memproses konfirmasi pembayaran seperti pada Gambar 5.

c. Proses Pengiriman

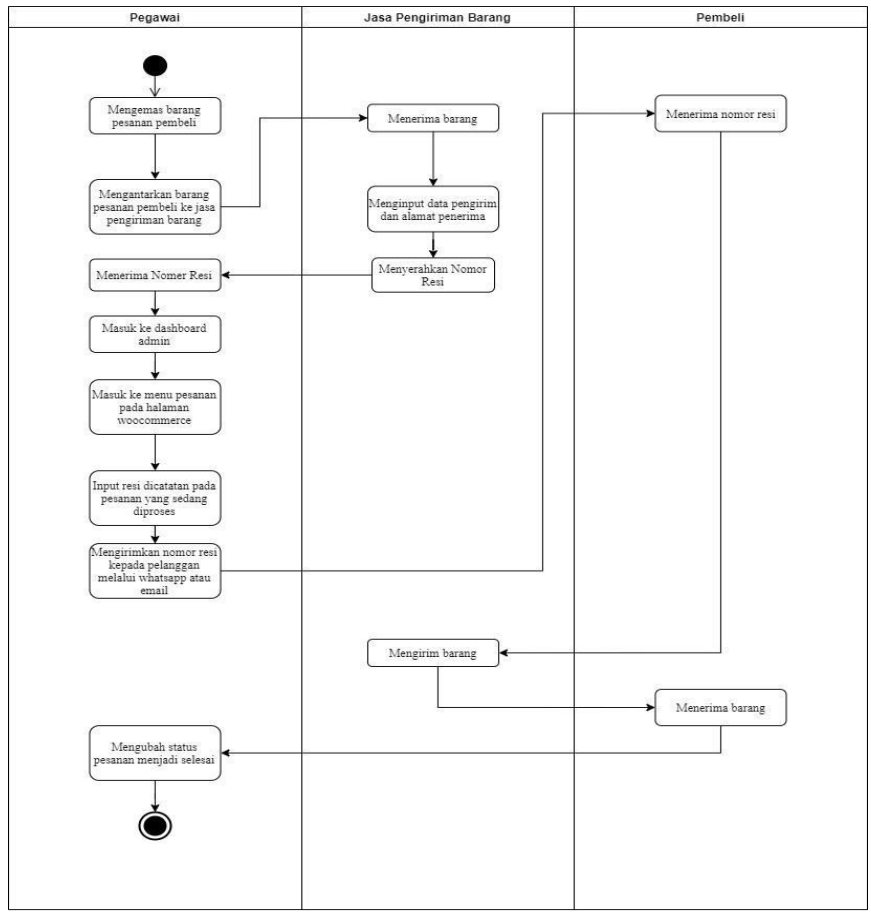

Gambar 6. Proses Pengiriman Barang

Kegiatan yang dilakukan oleh pegawai dengan mengemas barang pesanan lalu mengantarkan barang tersebut kepada jasa pengiriman barang. Setelah mendapatkan nomo resi dari jasa pengiriman barang, pegawai menambahkan nomor resi di catatan pada pesanan yang sedang diproses pada website. Pegawai juga mengirimkan nomor resi kepada pembeli melalui whatsapp atau e-mail. Pegawai juga akan mengubah status pesanan ketika barang sudah diterima oleh pembeli seperti pada Gambar 6. 


\subsection{Aturan Bisnis}

Pada kegiatan bisnis yang berlangsung dibutuhkan aturan bisnis yaitu jika pembeli melakukan pembelian setelah melewati jam operasional maka pesanan tersebut akan diproses dihari berikutnya, pembelian akan diproses jika sudah melakukan konfirmasi pembayaran dan terkonfirmasi oleh perusahaan, pengiriman hanya dapat dilakukan menggunakan jasa pengiriman yang ditetapkan perusahaan, produk yang telah dibeli tidak dapat ditukar, kecuali bila kesalahan atau kerusakan berasal dari perusahaan dan pembeli hanya dapat melakukan pembayaran ke rekening yang telah ditetapkan.

\subsection{Use Case Diagram dan Deskripsi Use Case}

Use Case Diagram menggambarkan tentang kegiatan antara aktor [7]. Adapun aktor yang ada adalah pelanggan, pegawai, dan pelanggan dengan sistem E-Commerce yang akan diterapkan seperti pada Gambar 7.

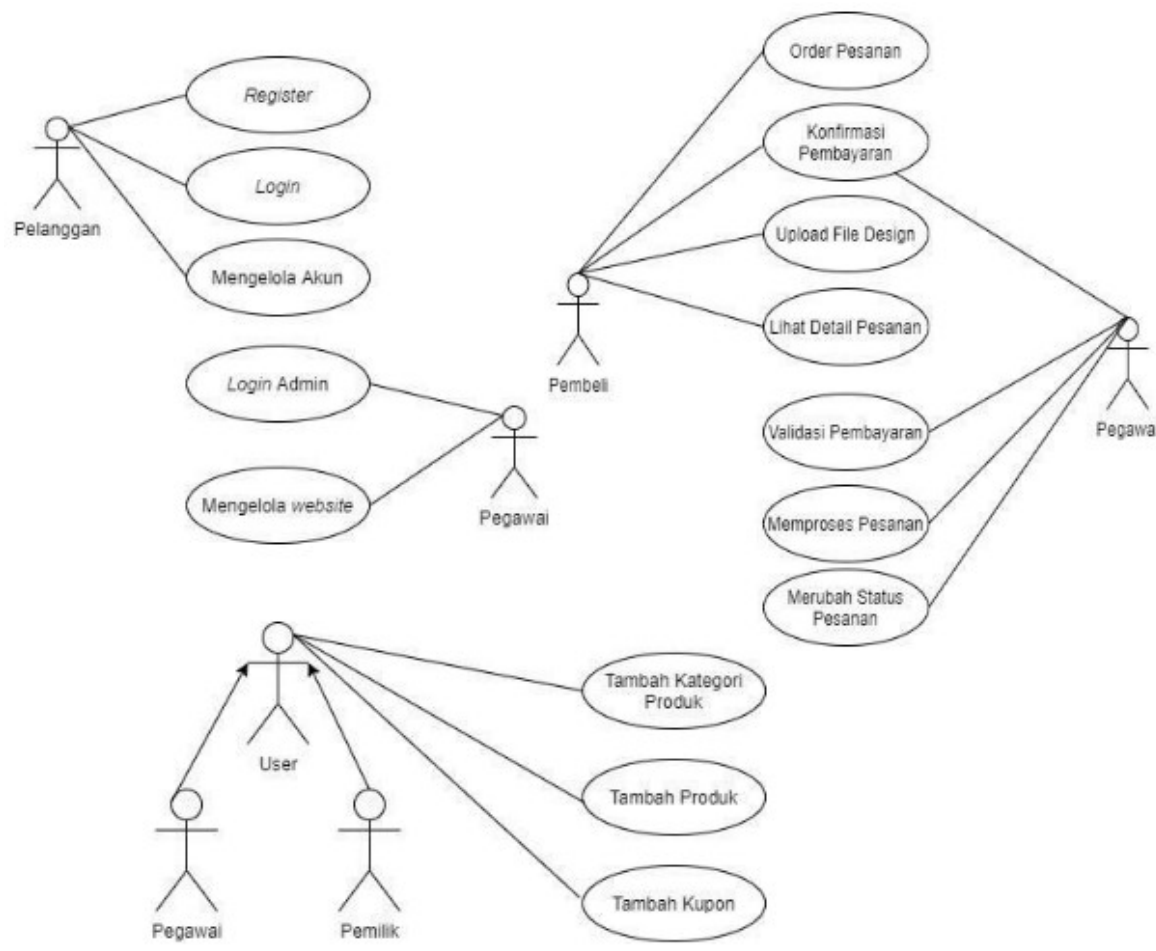

Gambar 7. Use Case Diagram

Pada Use Case Diagram Gambar 7 menjelaskan tentang alur pelanggan mendaftarkan akun pada website. Pelanggan belum memiliki akses login dan ingin mendaftar untuk melakukan pembelian product pada website. Pelanggan mengakses website dan masuk ke halaman my account. Pelanggan mengisi nama lengkap, username dan password. Jika sudah selesai, pelanggan mengklik tombol register maka data pelanggan akan tersimpan dan sistem akan mengirimkan notifikasi email. Post Condition: Pelanggan sudah mendaftarkan akun pada website serta pelanggan mendapat notifikasi email dan pelanggan sudah dapat login pada website. Pelanggan mengakses halaman website dan menuju halaman shop atau categories untuk memilih atau memesan product. Setelah memilih product, pelanggan mengklik tombol add to cart maka product tersimpan di cart. Pelanggan dapat memesanan lagi dengan kembali ke halaman shop. Pelanggan memilih kurir yang tersedia pada website. Pelanggan memilih kurir yang tersedia pada website. Kemudian akan tampil harga shipping dan kurir yang telah di pilih oleh pelanggan. Proses checkout yang dilakukan pelanggan. mengakses website dan masuk ke halaman checkout. System menampilkan review order yang di pesan dan pelanggan mengisi data diri seperti shipping atau alamat shipping serta memilih layanan kurir.Setelah mengisi data diri, pelanggan mengklik place order untuk menyimpan data shipping. Setelah pelanggan mengklik place order, pelangan akan mendapat email notifikasi. Setelah pelanggan melakukan checkout, admin akan mengirimkan email notifikasi melalui email.Admin akan mengirimkan email notifikasi yang berisikan total jumlah pembayaran yang harus di bayarkan oleh pelanggan. Pelanggan melakukan payment confirmation. Setelah pelanggan melakukan checkout, admin akan mengirimkan email notifikasi melalui email. Admin akan mengirimkan email notifikasi. Pelanggan melihat 
invoice Pelanggan mengakses website dan masuk ke halaman my account Pelanggan mengisi username dan password lalu klik login Akan muncul halaman dashboard pelanggan jika pelanggan berhasil login.

Alur pembuatan report atau laporan Admin setiap bulannya yang akan diberikan kepada pemilik. Admin login pada halaman back-end website. Setelah admin berhasil login, admin memilih menu woocommerce dan mengklik menu report yang diinginkan. Admin membuat report yang nantinya akan diberikan kepada pemilik. Setelah dibuat, admin mengklik tombol export. Maka report yang telah dibuat akan tercetak dalam bentuk pdf.

\subsection{Rancangan Layar}

Rancangan layar dibuat untuk mempermudah pelanggan dalam melakukan belanja online dimulai dari tampilan Beranda menampilkan artikel, layar Kategori Produk menampilkan seluruh produk yang ada. Pada rancangan layar checkout menampilkan total yang harus di bayar dan transfer bank. Layar Konfirmasi Pembayaran menampilkan data pembayaran seperti nama, no.order, email, no.handphone,

tanggal transfer, jumlah transfer, bank transfer, nama pemilik rekening dan bukti transfer, Layar Upload Design menampilkan pengisian data pesanan dan desain yang akan diupload seperti pada Gambar 7. Layar Akun Saya menampilkan pengisian data pelanggan.

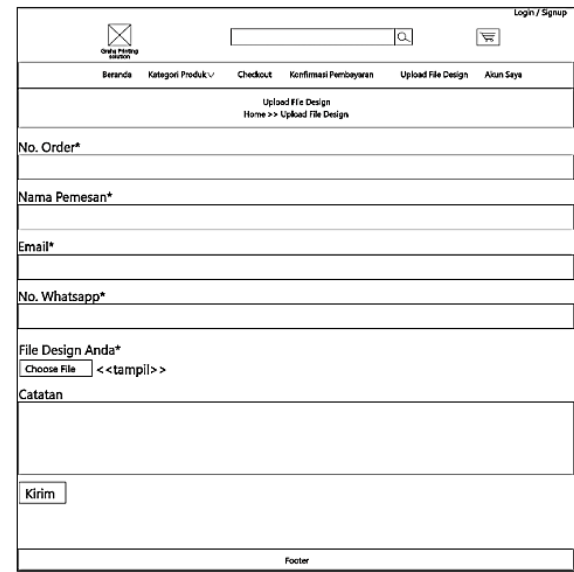

Gambar 8. Usulan form upload desain sesuai keinginan pelanggan

Gambar 8 menampilkan usulan form agar mempermudah pelanggan mengirimkan desain yang diinginkan yang selama ini dilakukan dengan menggunakan email atau aplikasi whatsapp.

\subsection{Search Engine Optimization (SEO)}

Search Engine Optimization (SEO) adalah serangkaian proses yang dilakukan secara teratur (baik di halaman maupun di luar halaman), dan dirancang untuk meningkatkan kuantitas dan kualitas lalu lintas situs web melalui mesin pencari seperti Google, Baidu dengan mekanisme atau algoritma operasi mesin telusur untuk mengakses laman web tertentu [8]. SEO atau optimasi mesin pencari, adalah cara untuk memaksimalkan situs web agar terindeks oleh mesin pencari dengan lebih baik. Perujukan teknis dilakukan melalui proses yang sistematis. Dengan kata lain, teknis SEO harus mengikuti aturan yang mengacu pada mesin pencari tertentu [9].

Strategi SEO yang digunakan adalah SEO On Page yaitu mengoptimasi halaman dan isi website agar dapat diindex oleh mesin pencari. Plugin yang digunakan adalah Yoast SEO [10]. Hasil optimasi Yoast SEO dapat dilihat pada Gambar 9 . 
INDONESIA JOURNAL INFORMATION SYSTEM (IDEALIS)

Volume 4, Nomor 2, Juli 2021

ISSN 2684-7280 (online)

Halaman 197-204

available online at http://jom.fti.budiluhur.ac.id/index.php/IDEALIS/index

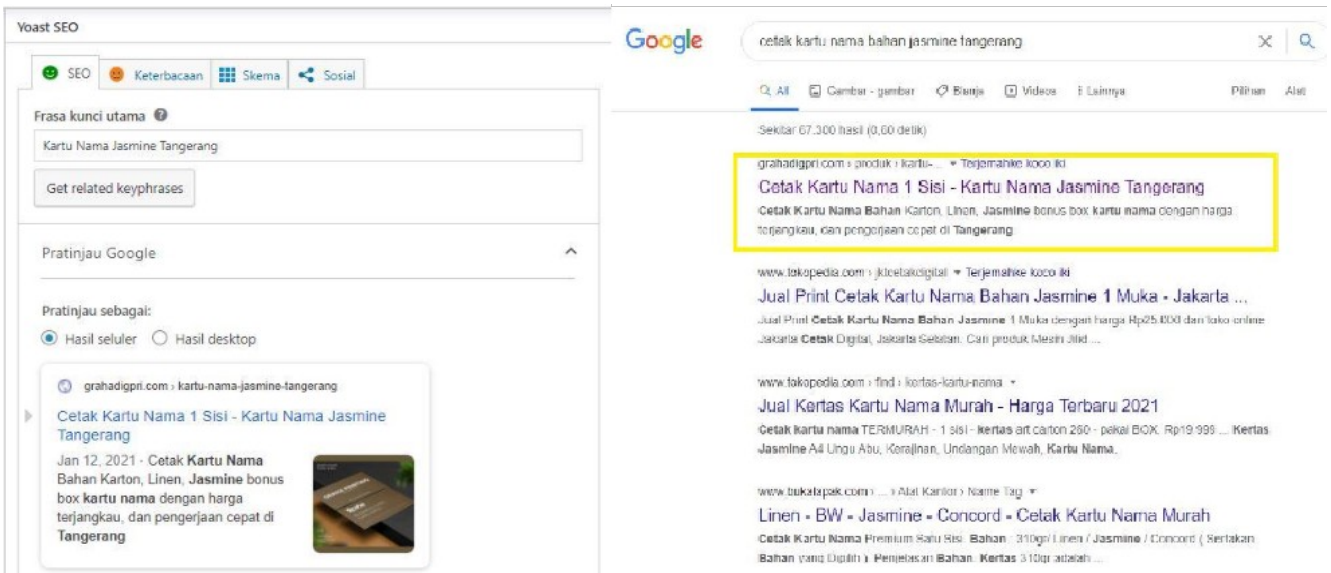

Gambar 9. Hasil Optimasi SEO di mesin pencari Google

Dari Gambar 8 ditampilkan hasil optimasi SEO yang diusulkan sehingga terindex di mesin pencari Google.

\section{KESIMPULAN}

Dari hasil pembahasan, dapat disimpulkan :

a. Dengan adanya website E-Commerce, perusahaan dengan mudah melakukan promosi dan menyampaikan informasi menggunakan fitur Search Engine Optimization (SEO), sehingga dapat memperluas jangkauan pasar dan mendapatkan pelanggan baru.

b. Pelanggan mudah mengetahui jenis bahan yang digunakan dengan melihat varian pada halaman produk.

c. Pelanggan mudah mengetahui jenis layanan percetakan yang tersedia pada halaman kategori produk.

d. Pemilik toko dapat mengetahui cara untuk meningkatkan penjualan setiap harinya dan penjualan bisa lebih maksimal karena pelanggan dapat melakukan transaksi secara online dengan mengunjungi situs.

e. Pemilik dapat memegang kendali penuh terhadap penjualan dan pengelolaan website E-Commerces sesuai keinginan pemilik serta dapat membangun brand.

\section{DAFTAR PUSTAKA}

[1] F. Ramadhan and L. Fajarita, "Implementasi Rancangan E-Commerce Pada Surya Timur Collection Dengan Metode Business Model Canvas (Bmc) Berbasis Content Management System (CMS),” 2020.

[2] A. Widyanto and H. Patrie, "Implementasi Penjualan Bebasis E-Commerce Pada Toko Synergie Motor," J u r n a l I D E A L I S, 2020.

[3] R. Hayati, “Pengertian Teknik Analisis Data, Jenis, dan Cara Menulisnya,” Penelitian Ilmiah.com. 2019.

[4] Y. Aryasuta and B. P. Cahya, "Penerapan Business Model Canvas Untuk Meningkatkan Penjualan Peralatan Beladiri Pada Toko Danis," Idealis, 2020.

[5] L. A. Saputra and S. Samsinar, "Penerapan Business Model Canvas Dalam Membangun Web Commerce (Studi Kasus Toko Pusatsneakers_Jkt),” INOVTEK Polbeng - Seri Inform., 2020, doi: 10.35314/isi.v5i1.1320.

[6] S. Mukaromah, D. P. Utami, and I. A. Wicaksono, "Penerapan Business Model Canvas sebagai Strategi Bisnis Manisan Carica di Cv Yuasafood Berkah Makmur (Studi Kasus di Cv Yuasafood Berkah Makmur Desa Krasak Kecamatan Mojotengah Kabupaten Wonosobo),” Surya Agritama J. Ilmu Pertan. dan Peternak., 2020, doi: 10.37729/suryaagritama.v9i2.723.

[7] A. Dennis, H. B. Wixom, and D. Tegarden, Systems Analysis Design with UML Version 2.5: An Object-Oriented Approach. 2015.

[8] A. Nurbawani, "Pengaruh Pemanfaatan Teknologi Search Engine Optimization (SEO) Dan Promosi Penjualan Terhadap Jumlah Penjualan Buku Secara Online,” JPEKBM (Jurnal Pendidik. Ekon. Kewirausahaan, Bisnis dan Manajemen), 2018, doi: 10.32682/jpekbm.v2i1.750.

[9] A. Sofyan, E. Ferdianto, R. Rahmawati, and R. K. Aldi, "Pengaruh Search Engine Optimization (SEO) Dan Riset Kata Kunci Terhadap Pendapatan Toko Online,” Indonusa Conf. Technol. Soc. Sci., 2019.

[10] F. A. Irfannudin and A. U. Hamdani, "Implementasi Sistem E-Commerce Pada Guna Motor Berbasis Content Management System (Cms) Wordpress," I D E a L I S, 2020. 